\title{
RETÓRICAS DE LA AUTENTICIDAD \\ EN EL CAPITALISMO AVANZADO ${ }^{1}$
}

\author{
JOAN FRIGOLÉ ${ }^{2}$ \\ Universidad de Barcelona
}

Resumen: El texto analiza la relación entre la retórica de la autenticidad en los medios de comunicación y los cambios que el capitalismo avanzado impuso en la producción y el mercado de bienes. Ideología de autenticidad y cultura son conceptos fundamentales para entender el proceso de producción de autenticidad. Cultura significa aquí modelos conceptuales, específicamente los de patrimonio y biodiversidad, que han contribuido a descubrir nuevas fuentes de valor y nuevos valores, que devienen nuevos bienes materiales o inmateriales. El texto analiza también los significados de autenticidad para su conversión en un término analítico.

Palabras Clave: autenticidad, patrimonio, biodiversidad, capitalismo.

AвSTRACT: The paper analyses the relationship between the rhetoric of authenticity in the media and the transformations that the late capitalism imposed over the production and the market of goods. Ideology of authenticity and culture are fundamental concepts to understand the process of production of authenticity. Culture means here conceptual models, specifically those of heritage and biodiversity, which contributed to identify new sources of value and new values, which become new material or immaterial goods. The paper also analyses the meanings of authenticity in order to convert this concept into an analytic term.

KEYwORDS: authenticity, heritage, biodiversity, capitalism.

\section{Introducción}

El objetivo principal de este texto es analizar las retóricas de la autenticidad con sus lenguajes, símbolos, narrativas y formas codificadas de comunicación y

${ }^{1}$ Con el apoyo del Proyecto (CSO2011-29413) «Patrimonialización y redefinición de la ruralidad» del Ministerio de Educación y Ciencia y Programa Feder.

2 frigole@ub.edu 
su relación con la economía política del capitalismo avanzado. Las retóricas de la autenticidad predican una determinada cualidad de bienes y servicios, cuyo consumo genera distinción social.

La atribución de autenticidad es la última operación o fase de un proceso de producción de autenticidad en el que intervienen tres factores básicos: la ideología, la cultura y la economía política.

El concepto de autenticidad surge de una estructura de símbolos y de términos. Denomino ideología de autenticidad a esta estructura de símbolos. La selección de los símbolos y su estructuración obedecen a la lógica de una cultura, es decir, la ideología de autenticidad está determinada culturalmente.

Mi definición de cultura está condicionada por la relación que establezco con el capitalismo avanzado. Cultura designa un conjunto de modelos conceptuales generales aplicables a la cultura, la sociedad y la naturaleza consideradas como entidades específicas. Estos modelos conceptuales, creación de especialistas de diversas disciplinas, son un referente fundamental para las instituciones, incluido el estado, y la población de una época, porque hacen posible pensar e identificar nuevas fuentes de valor. La selección y estructuración de estos modelos generales obedece a la lógica del capitalismo.

Heinich se refiere a una «economía de la autenticidad» (2012: 256) y Comaroff y Comaroff (2011) a una «economía de la etnicidad». Englobar estas economías en el marco de una economía política de la autenticidad, permite plantear el papel del estado y de las instituciones gubernamentales transnacionales en el descubrimiento y creación de nuevos tipos de riqueza y en la apropiación por parte de ciertas clases o sectores de población. He tomado como referente la propuesta de Wolf de que «los criterios de la antropología deben ser repensados a la luz de una economía política nueva y orientada históricamente» (1987: 9).

Con el término capitalismo avanzado me refiero al capitalismo que a partir de finales de la década de 1960 experimentó dos cambios que afectaron al sistema de producción y al mercado. En relación al primero: «La producción en masa ha sido modificada con el fin de proponer bienes más diversos, menos duraderos y más rápidamente sustituibles (producción de series limitadas, multiplicación de las opciones ofrecidas al consumidor...), frente a los productos estandarizados del fordismo» (Boltanski y Chiapello 2002: 557). La producción de bienes diferenciados se complementó con la introducción de un nuevo tipo de recursos, los 
bienes considerados auténticos, en la esfera de la circulación mercantil. Boltanski y Chiapello denominan mercantilización de lo auténtico a este segundo mecanismo que "consiste en la explotación de los seres, bienes, valores y medios que, a pesar de haber sido reconocidos como constitutivos de riquezas, y hasta como «tesoros» (...), aún quedaban fuera de la esfera del capital y de la circulación mercantil» (2002: 559) ${ }^{3}$. Comaroff y Comaroff se refieren también a la ampliación del mercado con la introducción de un nuevo tipo de bienes: «El notorio desplazamiento de la producción de valor de lo material a lo inmaterial —la venta de conocimientos y propiedad intelectual, la venta de experiencia, afectos y modos de autoproducción - indica que han ingresado al mercado dominios de la existencia que otrora le eran ajenos» (2011: 50).

Expuestos sumariamente los conceptos, retomo la relación entre economía política, cultura, ideología y retórica de la autenticidad desde el punto de vista de su contribución al proceso de producción de mercancías denominadas auténticas. La cultura contribuye con modelos generales que permiten pensar e identificar valores nuevos, que devendrán bienes materiales o inmateriales. La ideología de la autenticidad atribuye mediante una variedad de términos, que expresan la pluralidad de significados de la estructura de símbolos, una cualidad — la autenticidad - a los valores/bienes definidos culturalmente. La economía política transforma esos valores/bienes nuevos con una cualidad nueva en mercancías diferenciadas y las incorpora al mercado con el fin de convertirlas en capital. La retórica de la autenticidad es una de las prácticas orientadas por la ideología y el imaginario de la autenticidad. La secuencia lineal simplificada es: bien + cualidad $=$ mercancía + retórica $=$ capital. Haber postulado una jerarquía de determinaciones entre variables no implica que no exista una gran variedad de determinaciones recíprocas, sobre todo si se considera desde el punto de vista de un caso concreto.

Patrimonio es un viejo concepto que contemporáneamente ha experimentado una enorme apertura semántica y se ha convertido en un concepto general que hace posible pensar e identificar nuevas fuentes de valor en los ámbitos de la

3 Coincidencia en la cronología del cambio: En la década de 1970, en Inglaterra, «la industria del patrimonio se convirtió súbitamente en el gran negocio» (Hewison en Harvey 2004:106), y en Francia, fueron objeto de políticas patrimoniales «desde los monumentos históricos a los animales salvajes pasando por los sitios naturales, los paisajes o más todavía el patrimonio natural o genético.» (Lesourne en Lefeuvre 1990: 29). En 1972, la UNESCO votó la Convención para la protección del patrimonio cultural mundial. En 1973, McCannell publicó su influyente artículo «Staged Authenticity» sobre la relación entre culturas nativas y turismo. 
cultura y de la naturaleza, fuentes de valor que no son evidentes por si mismas. La mediación de este concepto y de otros permite identificarlas. Patrimonio designa un valor/bien destacando su asociación o referencia con un origen y a la vez predica el significado y el valor de un origen para una determinada realidad. El concepto de patrimonio ni incluye ni excluye la mercantilización, como tampoco incluye ni excluye la conservación. Las ideas de mercado y de conservación no son inherentes al concepto general de patrimonio. Las asociaciones de patrimonio con mercado o políticas de conservación provienen de la economía política, dependen de políticas económicas específicas.

Autenticidad define una cualidad por relación o asociación con un origen. La referencia común a origen crea una sinonimia entre patrimonio y autenticidad. En teoría, las realidades con atributos de autenticidad son patrimonializables, pero en la práctica ello depende de políticas económicas específicas. Sin autenticidad no puede existir el patrimonio, pero no toda la autenticidad es convertida en patrimonio.

La apertura semántica del término patrimonio y sus múltiples variantes ${ }^{4}$ evocan una vastísima reserva de autenticidad en el ámbito de la cultura y de la naturaleza, que es lo que el mercado aprecia y demanda. La relación entre los conceptos de patrimonio y autenticidad pone de relieve la interacción entre cultura e ideología. El concepto patrimonio, un modelo general de la cultura del capitalismo avanzado, difunde una concepción de la realidad, que es reforzada por la ideología de la autenticidad. El término autenticidad transfiere prestigio al origen, el referente básico para el concepto patrimonio.

Si el término patrimonio designa y generaliza un valor en los ámbitos de la cultura y de la naturaleza, el término biodiversidad designa y generaliza también un valor en el ámbito de la naturaleza y la cultura ${ }^{5}$. Ambos conceptos son estratégicos para el capitalismo avanzado por cuanto contribuyeron a ampliar el universo de los valores susceptibles de ser convertidos en capital. Sus características conceptuales no son un obstáculo para ello, al contrario. Davallon señala «la relativa inestabilidad» de la noción de patrimonio, porque «designa

\footnotetext{
${ }^{4}$ Heinich utiliza la expresión «la inflación patrimonial» como título de un capítulo para referirse a algo parecido. (2012: 15) Considero que la apertura del concepto patrimonio hizo posible dicha inflación.

5 Guillaume afirma que «la preocupación por la ecología y el pasado son valores refugio de las sociedades modernas» (DUPRÉ 2005: 398).
} 
realidades contradictorias». (2010: 39). Su flexibilidad contribuyó a convertirlo en un concepto general y ello posibilitó el fenómeno de la inflación patrimonial. La sociedad no espera a que los académicos definan el término o lo substituyan por otro, como el de patrimonialización, para eludir los problemas indicados. Marty, Vivien, Lepart y Larrère (2005) señalan que la imprecisión y ambigüedad rodea al término biodiversidad, pero ello no impide el consenso sobre el hecho de que este término designa «un bien general, independiente, que a causa de su vulnerabilidad, requiere de una atención especial» (Pinton, 2001: 331).

El concepto biodiversidad se impuso con rapidez en la década de 1980 asociado con «estrategias geopolíticas e industriales» (Aubertin, Boisvert y Vivien, 1998; 7).

Biodiversidad como valor proyecta una percepción de la naturaleza como un ámbito de riquezas o tesoros naturales. Esta concepción de la naturaleza se refuerza mediante el concepto capital natural, que introduce una concepción de la naturaleza como valor de cambio en el marco de una economía verde o de una economía política verde que implica a investigadores, estados e instituciones transnacionales. El análisis de los niveles de biodiversidad añade algunas especificidades al marco general. En el nivel de la biodiversidad genética, los genes y la información genética fueron conceptuados como recursos genéticos sobre los que se planteó de forma prioritaria la cuestión de los derechos de propiedad por parte de las empresas de biotecnología en los ramos de la producción de simientes, fármacos, cosméticos, etc., y de soberanía por parte de los estados. En las décadas de 1970 y 1980 la declaración internacional de protección de los recursos genéticos e incluso la declaración como patrimonio común de la humanidad, independientemente de su efectividad real, enfatizaron aún más el valor estratégico de estas riquezas originales o de estos valores de uso puros, según la terminología de Boltanski y Chiapello (2002).

Cuando se considera la biodiversidad en términos de especies y ecosistemas, su asociación con los conceptos capital natural y economía verde promueve una concepción de la naturaleza que permite identificar servicios y funciones ambientales a los que se asigna o se puede asignar un precio por el uso de recursos de los ecosistemas. Biodiversidad y economía verde definen una perspectiva global que hace posible la creación de mecanismos financieros globales como las reducciones certificadas de emisiones, es decir, bonos vendibles en mercados internacionales de emisiones, y la reducción de emisiones vinculada a la deforestación y a la degradación de los bosques. Un ejemplo de cómo funcionan estos instrumentos 
financieros ambientales: comunidades indígenas de la sierra de Oaxaca (México) ofrecen a empresas lejanas certificados garantizados que avalan la absorción de dióxido de carbono por el ecosistema de bosque de montańa en que viven, para compensar sus emisiones de dióxido. Las empresas pagan para que los árboles sigan en pie y los indígenas cobran por el mantenimiento de su ecosistema amenazado por la deforestación.

El desarrollo de «sectores ecológicos emergentes» tales como las energías renovables, la gestión de residuos, el ecoturismo, la agricultura ecológica, etc., es otra de las respuestas uniformes contra la pérdida o erosión de biodiversidad.

Esta interpretación de biodiversidad se enmarca dentro de una concepción de la naturaleza como recurso, vinculada a una tradición científico-técnica (Van Koppen, 2000: 300). La autora distingue también la concepción de «la naturaleza como arcadia», que resalta los valores moral, estético y emocional de la naturaleza.

La interpretación dominante de biodiversidad, asociada con una concepción instrumental de la naturaleza, coexiste con una interpretación próxima a la concepción de la naturaleza como arcadia, que se corresponde con una biodiversidad representada fundamentalmente por animales salvajes, selvas tropicales y otros ecosistemas salvajes amenazados y que suele ser el objetivo principal de los movimientos conservacionistas.

Ambas interpretaciones de la biodiversidad son un referente para la ideología y la retórica de la autenticidad y permiten entender el protagonismo de lo verde, una metonimia, y del árbol, una metáfora, en el imaginario medioambiental. Algunos ejemplos de las asociaciones del color verde: «economía verde», «empleo verde», «emprendedor verde», «industria verde», "crédito verde», «hoteles verdes», «vocación verde», "estado verde», «santuario verde», «lo verde debe ser el nuevo sueño colectivo»... El árbol condensa valores que oscilan entre el polo económico, con sus asociaciones con la contabilidad ambiental y la compensación obligatoria, y el polo del don a la naturaleza. Lo verde y el árbol condensan un conjunto de atributos abstractos tales como natural, sostenible, ecológico, renovable, etc., considerados fundamentales para el pensamiento medioambiental.

La proliferación de atribuciones de autenticidad se corresponde con la estrategia del capitalismo avanzado de incorporar a la esfera de la circulación mercantil un nuevo tipo de bienes y la cultura contribuye a ello mediante la 
creación de modelos generales que conceptúan e identifican esos nuevos bienes susceptibles de convertirse en nuevas mercancías. Patrimonio y biodiversidad son modelos generales que definen valores/bienes que movilizan a los agentes de acuerdo con percepciones estructuradas por las dicotomías pérdida/protección y destrucción/salvación. En torno a ellas se articulan redes, coaliciones, movimientos, instituciones, etc. con proyectos de apropiación y control de signo opuesto.

Expuesto el marco conceptual general, el texto se centra en el análisis de la polisemia del concepto autenticidad, polisemia que muestran los ejemplos siguientes: «uno de los más auténticos del mundo», predicado de un territorio; «regreso a lo auténtico», de una gastronomía; «la exclusividad ahora se llama autenticidad», de un estilo de vida; «los auténticos vestigios de la violencia», de una matanza étnica; «autenticidad hecha a mano», de un objeto; «autenticidad», de los productos de lujo. Autenticidad articula campos semánticos diversos.

\section{Definición de autenticidad}

El objetivo de este apartado es inventariar los referentes y significados de autenticidad para su construcción como concepto analítico. Tomo en consideración los siguientes referentes: tiempo, espacio, naturaleza, valor de uso y pequeña producción.

Según Heinich, autenticidad «remite al origen» (2012: 256). Said (en Herzfeld, 1999: 107-109) distingue entre origen e inicio, una distinción que asocia con la dicotomía naturaleza y cultura. Autenticidad como origen/ inicio condensa los significados de original, primigenio, primero, ancestral. Sobre esta significación se construyen otros significados del término. La continuidad real o imaginada en relación a un origen está en la base de conceptos y significados específicos como pureza de sangre o etnicidad.

Según Davallon, autenticidad «describe la relación entre el objeto y el lugar de origen así como el estatus epistémico que la sociedad atribuye a esta relación y especialmente como la produce» (2010: 55). En este sentido, caracteriza un tipo de lengua: «En contraste con la voz pública y anónima, la voz auténtica es sentida como profundamente arraigada (...) en un territorio social y geográfico» (Woolard, 2008: 183). La autenticidad concebida en términos de un vínculo con el lugar de origen da pie a metáforas como raíz y conceptos como autoctonía y tipicidad. 
El concepto mercantilización de lo auténtico, que Boltanski y Chiapello crearon a partir de la dicotomía entre valor de uso y valor de cambio, descubre otro significado de autenticidad. Lo auténtico tiene como referente «un original que no sea una mercancía, sino un valor de uso puro, definido por una relación singular con respecto a un usuario» (2002: 559). El original, situado en el margen de la esfera del capital, puede ser incorporado a ella como valor de cambio, precisamente por la cualidad que le atribuye su origen y por su evocación continuada del mismo, por su posición fuera del mercado.

La naturaleza construida simbólicamente mediante concepciones como «naturaleza como arcadia» y «naturaleza como recurso» (Van Koppen, 2000), y conceptos tales como los de biodiversidad, ecología, diversidad biológica y otros es también un referente para autenticidad. «Retorno a la naturaleza» y «giro hacia la naturaleza» son expresiones que incorporan una referencia a origen y por ello connotan un movimiento hacia la autenticidad en los ámbitos de la producción, el consumo y los estilos de vida. Natural, arcádico, salvaje, «eco» y «bio» son algunos de los términos o raíces que connotan autenticidad.

El modelo de los cuatro universos de producción de Storper (citado por Murdoch and Miele, 1999: 472), construido a partir de la intersección de dos ejes, uno vertical definido por la oposición entre estandarizado y especializado y otro horizontal, por la oposición entre genérico y específico, permite descubrir otros referentes para autenticidad. La pequeña producción especializada, artesanal, hecha a mano con esmero, fiel a la tradición — una forma de referirse al pasado-, asociada con un territorio específico y la naturaleza como referente, como en el caso de los materiales - cuero, conceptuado como material noble, versus plástico, por ejemplo- adquiere la connotación de autenticidad. En un mundo en el que la compresión del tiempo es una de sus características principales, la lentitud asociada con la pequeña producción evoca autenticidad. La producción especializada resulta indispensable para la reproducción de productos auténticos, según la definición de mercantilización de lo auténtico (Boltanski y Chiapello, 2002), lo cual acrecienta su connotación de autenticidad. La pequeña producción especializada no se opone a capitalismo, sino que forma parte de él. Cuando un empresario de productos exclusivos dice que el estado debería «ayudar a los artesanos, porque son el futuro", está afirmando la importancia de los productos auténticos para el consumo, la distinción social y el desarrollo del capitalismo.

La producción industrial estandarizada asociada con una concepción instrumental de la naturaleza se aleja del dominio de lo natural y por ello de lo autén- 
tico. Un ejemplo lo ofrece la producción industrial de alimentos, que substituye componentes y/o procesos naturales por industriales (Murdoch et al., 2000). Por ello los alimentos industriales son percibidos como los menos naturales y en consecuencia, los menos auténticos. El modelo de los cuatro universos de producción permite entender no sólo cómo la naturaleza es tratada en relación a la producción, sino también qué imágenes de la naturaleza se utilizarán en el marketing de marcas y productos.

La polisemia del término autenticidad resulta de la multiplicidad de referentes y significados, de las asociaciones entre ellos, y también de las oposiciones que se establecen con otros referentes y significados. Estos significados sustentan una noción de autenticidad que alimenta procesos de patrimonialización y mercantilización de lo auténtico, mecanismos básicos de la economía política del capitalismo avanzado. La superposición y la acumulación de significados sobre una realidad incrementa su autenticidad y con ello su valor potencial para el mercado de bienes auténticos, como evidencia la importancia atribuida recientemente a algunas razas de caballos por la confluencia de diversos orígenes (temporal, espacial y social) y un valor fundamentalmente de uso, debido a su marginación a causa de los avances tecnológicos (Bindi, 2012).

\section{Las retóricas de la autenticidad}

En este apartado ilustro los lenguajes, símbolos, narrativas y formas codificadas de comunicación que conforman las retóricas de la autenticidad con ejemplos de distintos tipos de publicidad aparecidos principalmente en los medios de comunicación escritos entre los años 2009 y 2012.

Me centro en primer lugar en los lenguajes de la autenticidad.

En el ámbito de la moda del vestir el término cool define una tendencia o estilo. Cool se opone convencional y también a extravagante. Una definición positiva introduce una referencia al pasado y a la forma de producción. Así de una moda cool de vestir se puede decir que es moderna pero tiene «un toque vintage» $\mathrm{y}$ «un eco artesano», es decir, "hecho a pequeña escala, con buenos materiales y un cierto mimo, (...) el cliente no es tonto y se da cuenta de lo que es sincero y lo que no» (Aguilar, 2012: 22). Cool y sincero apuntan al valor de la autenticidad. 
En el ámbito de la agricultura, incluida la viticultura, lo autóctono cultivado puede constituir una expresión de la autenticidad: «las viejas cepas autóctonas», asociadas a veces con tierras de antiguos monasterios, en oposición a «modernas cepas importadas». El pasado y la autoctonía generan un valor de autenticidad para el presente que sintetiza el eslogan: «cepas viejas, vinos modernos». No se descarta el uso de tecnología moderna, pero se pone énfasis en los "procesos tradicionales», en «un modo de hacer natural». La secuencia puede ser la siguiente: "cultivo ecológico" identificado con un retorno a las prácticas "campesinas de toda la vida», "elaboración artesana» identificada con «hecho a mano» y bodega «ecológica y bioclimática». La autenticidad atribuida a todo el proceso. Cuando existe una continuidad de muchas generaciones de viticultores, el modelo de referencia puede no ser la penúltima, sino varias anteriores: «yo no quiero hacer la viticultura de mis padres, me interesa la de mi bisabuelo" (Fernández 2012:50). Autenticidad remite a un pasado lejano. Alice Feiring experta en vino ha utilizado la metáfora de la desnudez para dar visibilidad a un "nuevo mundo» de vinos que se producen «como hace miles de años» (Rivas, 2011). El par metafórico desnudo/vestido articula una serie de dicotomías explícitas o parcialmente implícitas. Desnudo se opone a vestido como natural se opone a artificial, es decir, producido con aditivos y artificios y con una idea preconcebida de cómo debe ser el vino. Desnudo significa también ecológico, sostenible, con personalidad, con corazón y real por oposición a impostura que condensa los significados de no ecológico y sin personalidad. El vino desnudo es un vino auténtico, el vino vestido es inauténtico.

En el ámbito de la gastronomía, el restaurante NOMA, acrónimo de los términos daneses nordik mad, comida nórdica, ocupa la primera posición del ranking mundial de restaurantes porque su modelo gastronómico es la máxima expresión de autenticidad. Su referente básico es el dominio de lo silvestre, icono de la naturaleza, de lo autóctono, de lo que estaba fuera del sistema gastronómico por ser considerado no adecuado o prestigioso y, por ello, con un valor fundamentalmente de uso, etc. El cocinero número uno se define a sí mismo y a sus 25 cocineros como: «exploradores gastronómicos» (Rodríguez, 2011: 34) y proyecta una imagen de naturalista y de recolector antes que de cocinero: «para mí es más importante ver dónde y cómo crece una baya o a una abeja polinizando una flor que va a formar parte de un plato único, que un kilo de caviar iraní» (Rodríguez, 2011: 35).

El giro hacia la naturaleza constituye la premisa básica del modelo gastronómico del NOMA. No obstante, los criterios de codificación del mismo no 
provienen directamente de la naturaleza, sino de una codificación previa de la naturaleza que forma parte del diseńo nórdico, convertido en marca, cuyas características son: calidad de vida, sencillez, limpieza, naturalidad, funcionalidad, pureza, frescura, sobriedad, elegancia, respeto por el medio ambiente y armonía con la naturaleza. En correspondencia, la comida del NOMA «es sutil, ligera, colorista, sin grasa, da la sensación de haber sido apenas acariciada en la cocina. Se come con los dedos. Se impone lo crudo. No hay sabores portentosos ni agresivos, ni grandes explosiones de sabor. (...) Es una gastronomía que sabe a tierra, a mar y a bosque» (Rodríguez, 2011: 42) ${ }^{6}$.

Las expresiones "comida verdadera», como en las frases "comprar por la red es acercarse a la comida verdadera», «tener en casa los sabores verdaderos de la comida", y "comida de verdad», eslogan de una cadena de supermercados de alimentos ecológicos, apuntan al valor de la autenticidad. Verdad, sinónimo de autenticidad, condensa los significados ecológico, biológico, natural, etc.

En consonancia con la prominencia de la referencia a la naturaleza en el imaginario de la autenticidad, los prefijos bio y eco aparecen con frecuencia y se consideran indicadores básicos de autenticidad. El prefijo bio se ha incorporado no sólo a etiquetas de productos alimentarios y no alimentarios, sino también a categorías sociales y estilos de vida como «biojoven, biojóvenes». El prefijo bio contribuye a expandir la noción de juventud, al no circunscribirla a la cronología sino fundarla en la biología y sobretodo en la apariencia física, y contribuye a definir un estilo de vida con un universo de productos y servicios específicos.

El número de términos con el prefijo eco es mayor. Algunos ejemplos: ecoturismo, eco-hotel, eco-ciudad, eco-aldeas (persiguen la autosuficiencia energética), eco-conducción (referida a pautas de conducción de automóviles), eco-tecnología, eco-diseño, eco-burbujas (tecnología de lavado), eco-ligera (agua embotellada), eco-finanzas (mercado de bonos de emisiones como instrumentos financieros contra el cambio climático), eco-cocina (recrea «sutiles paisajes autóctonos comestibles»), mente ecológica (referencia al reciclaje), eco-valor (puede referirse al valor de objetos reciclados), eco-responsable, eco-eficiente, eco-ciudadanas, «apúntate a lo eco», etc.

${ }^{6}$ Ver Frigolé (2012, apartado 3: «Eco-símbolos y marcas en un mercado global» pp. 180-182) y «La cocina del nuevo espíritu del capitalismo: el NOMA. Consideraciones en torno al valor de lo auténtico y otras convenciones de valor» (2011, 20 páginas, inédito). 
Algunos términos son objeto de una diferenciación semántica que se correlaciona con la creación de productos diferenciados. En un folleto se lee: «Apúntate a lo ECO. Si eres fan incondicional de lo natural, no puedes perderte los productos que Sephora tiene sólo para ti» y se establecen las siguientes distinciones: «Llamamos naturales a los que poseen ingredientes vegetales en mayor o menor proporción. Un producto bio debe contar con un 95\% de ingredientes naturales y al menos un $10 \%$ proceder de la agricultura biológica, sin colorantes, conservantes, perfumes sintéticos o sustancias animales. Y en uno eco, este porcentaje aumenta hasta el 50\%. Además, ambas clasificaciones deben tener la denominación de alguno de los organismos de control y certificación» (Smoda, especial Sephora, diciembre 2011). A la gradación conceptual le corresponde una gradación de autenticidad.

El prefijo eco puede formar parte de etiquetas que aspiran a devenir marcas como «ecoceutics», que diferencia ciertos establecimientos farmacéuticos de las farmacias tradicionales, asociadas sólo con la industria farmacéutica, y de los comercios de productos alternativos en el ámbito de la salud. Refuerzan la marca con una revista titulada «Ecovital».

La gran producción estandarizada en ámbitos considerados muy artificiales, como el de la producción química, utiliza también la retórica de la autenticidad en el marketing de sus productos. Un ejemplo: BASF, una multinacional del sector químico, ha creado «ecovio» (sic), una etiqueta para diferenciar un plástico nuevo: "Creamos química (letras de color verde) para que el compost ame el plástico (letras de color blanco)» (El País, 22 de noviembre de 2012). Unas bolsas transparentes con restos orgánicos junto a una tierra fresca en la que ha brotado una plantita con muchas hojas verdes, enlazadas ambas imágenes por un gran corazón verde, complementan el texto. La etiqueta creada mediante la reduplicación de prefijos significativos y la imagen de la planta verde evocan naturaleza y autenticidad. Aunque se trata de un producto industrial estandarizado, la frontera entre artificial y natural se vuelve tenue, dado que el elemento artificial está destinado a desaparecer y la imagen del árbol potencia el dominio de lo natural.

Se crean nuevos términos que reflejan el impacto del imaginario de autenticidad. Uno de ellos es el término «cero». La gran producción industrial sin usar directamente una referencia ecológica crea nuevos significados por aproximación a lo ecológico para generar especificidad dentro de la categoría de productos estandarizados generales. Son los productos industriales con la fórmula «cero», los con menos ingredientes químicos, los menos artificiales, los más cercanos a 
la categoría de natural. Un ejemplo de publicidad de un jabón corporal: «Sanex Zero\%: 0\% Parabenos, 0\% Colorantes, 0\% Phthalates, $0 \%$ Phenoxyethanol. Sanex Zero\% es una fórmula suave con la piel y biodegradable que contiene menos ingredientes químicos. (...) es sano para ti y para el medio ambiente porque sólo contiene los ingredientes necesarios.» El lenguaje «cero» es utilizado también por los movimientos que defienden los derechos de los animales y reivindican una relación libre de crueldad ( $0 \%$ crueldad) entre el hombre y los animales. En este caso, el lenguaje "cero» refleja una concepción moral de la naturaleza en oposición con una concepción instrumental de la misma. También usan el término "cero" movimientos que defienden el consumo prioritario de los alimentos del propio territorio. La etiqueta «kilómetro cero» condensa entre otros significados los de autóctono, fresco, verdadero, etc., en relación a los alimentos. El lenguaje «cero» predica grados de autenticidad diferentes según muestran estos ejemplos.

El lenguaje de la autenticidad se ramifica en torno a los cuatro referentes básicos: tiempo, espacio, naturaleza, valor de uso y pequeña producción y expresa una gradación de esta cualidad desde un centro hasta la periferia de este dominio semántico. Este lenguaje es el vehículo del imaginario de autenticidad, una ideología conformada por una cultura correspondiente al capitalismo avanzado y su reto de producir de forma imparable productos diferenciados que incorporen parte de los significados y valores de los bienes auténticos, que se incorporan simultáneamente a la esfera de la circulación mercantil. La gran producción de productos estandarizados se adapta a esta necesidad de diferenciación tanto en los ámbitos de la producción como de la comercialización, en el que el marketing asume un papel cada vez más importante, dado que envuelve a los productos con percepciones y emociones que no derivan del producto en sí sino del imaginario de la autenticidad. En este imaginario tienen un papel importante los símbolos, dado que son elementos estructurantes del mismo. Analizo a continuación el protagonismo del símbolo «semilla y árbol» en las retóricas de autenticidad que utiliza el marketing. Presento en primer lugar una serie de ejemplos:

Dos modalidades de publicidad llevadas a cabo por dos cadenas de hoteles:

«Como parte de la campaña «Planta un árbol en el jardín», el hotel Four Seasons México D. F. ofrece un kit de semillas por el donativo de 20 dólares que serán utilizados para comprar y cuidar árboles, los cuales serán donados al Bosque de Chapultepec. En el 50 aniversario de la cadena se pretenden plantar 10 millones de árboles en el mundo». (Mercado de Convenciones 85, 2011). 
«En este hotel, 5 toallas reutilizadas = 1 árbol plantado. En colaboración con el Programa de las Naciones Unidas para el Medioambiente, Ibis se compromete en la «Campaña mil millones de árboles». De esta manera, usted se une a otros muchos clientes que participan ya en esta iniciativa en 2500 hoteles del grupo Accor en los cinco continentes. Aquí, sus toallas plantan árboles».

La fundación Yves Rocher, vinculada a la empresa de cosmética del mismo nombre, impulsa el programa «Plantemos para el planeta». Desde marzo de 2007, se compromete ante el Programa de Naciones Unidas para el Medio Ambiente a plantar cinco millones de árboles a través de ONG especialistas de la repoblación en una decena de países, entre otros Brasil, India, Madagascar, Francia y Australia. La fundación, en asociación con el Instituto de Francia, patrocina también el programa «Tierra de mujeres», que ha premiado a doscientas eco-ciudadanas por sus acciones de protección del mundo vegetal en más de cincuenta países del mundo ${ }^{7}$.

La industria minera, dentro del modelo del productivismo, que causa un gran impacto sobre el medio ambiente y las poblaciones locales, utiliza la referencia al árbol para mejorar su imagen. Las industrias mineras en México publicitaron que habían plantado 2.8 millones de árboles en 2011.

La petrolera Repsol ha utilizado la imagen de un arbolito plantado en la sección inferior de un pequeño globo terráqueo con el texto: «Cuidar nuestro planeta es un premio para todos. Repsol es conocido por los índices internacionales más prestigiosos por su compromiso en materia de sostenibilidad y responsabilidad corporativa.» (Dirigentes, septiembre-octubre, 2011) La imagen evoca fragilidad y suscita preocupación y necesidad de cuidado, a la que se hace corresponder el compromiso y la responsabilidad de la empresa.

Examino otra forma de publicidad que contiene una referencia al árbol, en torno al cual se ha codificado una modalidad de comunicación indirecta entre empresa y consumidores y entre consumidores. Se trata de la publicidad de un nuevo coche de Volkswagen llamado «Touareg Hybrid»: «¿Quién dice que no se puede ayudar al planeta con estilo?» Contiene también la frase «el coche de lujo que el medio ambiente necesita». En una segunda página, una bolsita transparente con tres semillas con el siguiente mensaje: «Desprende la hoja, escanea el código y observa cómo a través de una hoja también puedes sembrar un árbol».

\footnotetext{
${ }^{7}$ http://www.yves-rocher-fondation.org
} 
Y luego, debajo de un gráfico: «comparte una foto de tu maceta». La publicidad pretende crear la imagen de una comunicación colectiva y de una comunidad de usuarios e intereses.

La imagen del árbol, símbolo fundamental en estas retóricas de la autenticidad, no es la de «siempre», sino una nueva, reconfigurada por la conjunción de tres modelos culturales: patrimonio, biodiversidad y economía verde. Es la imagen del árbol que adquiere un valor nuevo por los servicios ambientales que presta: por la cantidad de dióxido de carbono que absorbe y su contribución a la lucha contra la contaminación, principal enemigo de la biodiversidad. El árbol se constituye como factor de limpieza ambiental y de conservación de la vida. Encarna el significado de limpieza ambiental y por extensión otros significados de limpieza. La imagen del árbol reconfigurada por los modelos citados condensa también otros significados, entre los que destacan los de riqueza natural, capital natural, patrimonio natural, etc.

El árbol como encarnación y evocación de limpieza en el ámbito de los negocios: dos manos juntas sostienen tierra y un arbolito verde y el siguiente texto: «Negocios éticos. Las grandes y pequeñas empresas saben que sin buenas prácticas, las cuentas de resultados se resienten». ${ }^{8}$ De la misma manera que la limpieza ambiental hará posible el crecimiento del arbolito, la limpieza moral hará posible el desarrollo de la empresa.

La referencia al árbol, aunque sea un árbol muerto, es fundamental para aquellos productos que se sitúan en los límites de lo natural y por ello de lo auténtico. Un ejemplo de ello es la información que ofrece una cadena sobre algunas fibras artificiales que componen sus prendas de vestir. Del poliéster se destaca que es «el uso noble de los hidrocarburos, que son viejos bosques fosilizados», y de la viscosa que «antes de ser hilo, ha sido un árbol que se ha pasado 25 años transformando $\mathrm{CO}^{2}$ en celulosa a través de la fotosíntesis». No se afirma que sean fibras naturales, pero la asociación indirecta con el árbol las acerca al dominio de lo natural. Como en el lenguaje «cero» utilizado por la gran producción, los productos con esta etiqueta son los menos artificiales del dominio industrial y en la misma medida se aproximan a los límites del dominio de lo natural y de lo auténtico.

8 El País n. ${ }^{\circ}$ 1412: «Responsabilidad social corporativa», 25 de noviembre de 2012. 
Si antes he relacionado la diferenciación lingüística con la diferenciación semántica y la diferenciación de productos con la ideología de la autenticidad, ahora se le podría añadir la diferenciación organizativa, si consideramos la relación entre empresas, fundaciones, instituciones globales y ONG y las funciones que cada una asume. La relación entre ellas comporta el trueque de capital por capital simbólico. En el proceso de diferenciación organizativa intervienen otros factores como la economía política y las ventajas fiscales en el caso de las fundaciones, la cultura de la auditoría y la verificación, etc.

Presento otros ejemplos:

APP CARES, que es una de las papeleras más importantes de Asia, publicó en Le Monde —sería interesante conocer donde se publicita y donde no, para saber frente a qué audiencias quiere reforzar su marca-, un anuncio de un cuarto de página con el siguiente título: «Para descubrir nuestro compromiso a favor de la biodiversidad, siga nuestra la huella». La imagen: una gran huella de orangután marcada en el fango. A continuación el texto: «APP se toma muy en serio su misión de preservación del medio y patrocina diferentes programas de conservación: 106.000 hectáreas en el seno del Senepis Tiger Sanctuary, 10.000 hectáreas en la Reserva Natural Taman Raja, 172.000 hectáreas dedicadas a la Reserva de la Biosfera... proyecto especialmente reconocido por el programa de la UNESCO sobre el Hombre y la Biosfera, así como el Programa Orangután Kutai. Para que nuestra empresa prospere, sabemos que el medio en el que trabajamos debe prosperar igualmente» (9 de noviembre de 2011).

Las referencias a Santuario, Reserva natural, Reserva de la Biosfera, Programa de la UNESCO «El hombre y la biosfera», etc. indican una política de protección, una patrimonialización de diversos ámbitos naturales. La empresa no invierte en la protección de cualquier medio, sino en proyectos de patrimonialización reconocidos, en proyectos singulares que encarnan la imagen de naturaleza y biodiversidad, que son los que le permiten exhibir sus credenciales medio-ambientalistas frente al mundo. Es de notar que así como el árbol se ha convertido en icono de la naturaleza, el animal genérico, no. Los programas de protección de animales siempre se refieren a animales específicos.

La empresa Steltman comercializa un anillo llamado Safari con el siguiente reclamo: «la compra de un Steltman —en colaboración con los Parques de África- ayuda a conservar las reservas naturales». 
Las reservas naturales son una imagen fundamental de la naturaleza, encarnan la naturaleza salvaje y en cuanto tal la naturaleza prístina, la naturaleza que hay que salvar prioritariamente porque con sus características nos vincula al origen y por ello a lo auténtico.

Las empresas que utilizan las retóricas de autenticidad transfieren este valor a sus marcas y productos no sólo mediante el carácter de las iniciativas que patrocinan, sino también por asociar a ellas a instituciones y organizaciones conservacionistas.

Se han mencionado diversas modalidades de patrimonialización de la naturaleza en los ejemplos anteriores, que ampliaré con referencias al ámbito de la cultura. Patrimonialización consiste en un proceso de "producción cultural en el presente que recurre al pasado" (Kirshenblatt-Gimblett, 2001: 44) para producir un valor llamado patrimonio, que se identifica con autenticidad. Este concepto es necesario porque introduce una referencia a los agentes del proceso.

El primer ejemplo de patrimonialización se refiere a un pueblo de origen medieval en los Abruzos (Italia) que ha sido reconvertido en hotel de lujo. El creador del sello hotelero de calidad Design Hotels, al que pertenece el hotel, declara: «Nada de lo que vemos ha sido creado con artificio, todo sigue las estructuras crecidas naturalmente. El pueblo ha sido restaurado por completo para convertirse en hotel, se le ha devuelto la vida y con ello ha regresado también mucha gente joven para trabajar aquí. Y además, está rodeado de la naturaleza intocada del parque nacional de Gran Sasso. Autenticidad hasta en los más pequeños detalles, empezando por el jabón hecho a mano. Las instalaciones están reducidas al mínimo y la tecnología moderna se limita a lo imprescindible». El responsable de la realización del proyecto afirma: «Es primero un proyecto de preservación del patrimonio, tanto arquitectónico como paisajístico, y luego un hotel. Se utilizaron sólo materiales y técnicas artesanales locales recuperadas gracias a una investigación previa y a los testimonios de los más viejos de la zona. Algunos de ellos tenían más de 90 años, últimos testigos de una civilización y una cultura a punto de desaparecer. Muchos de los alimentos que se utilizan en el restaurante son de producción propia. Preparamos, por ejemplo, un guiso con unas lentejas típicas de la zona que hemos recuperado. Se cultivan a 1400 metros de altura, son muy pequeńas y están cargadas de hierro. Aquí se pueden todavía degustar los auténticos sabores de antaño. El reto es crear destinos turísticos sin dañar la personalidad, la esencia de un lugar. Proponemos descubrir una Italia auténtica» (Saile, 2010: 14). 
El hotel está concebido para producir experiencias auténticas en los viajeros mediante la patrimonialización del pasado, un proyecto radical compatible con la codificación, es decir, la selección de los aspectos conservables del lugar. Existe una correspondencia perfecta entre el proyecto de patrimonialización y la mercantilización de lo auténtico, dado que lo primero está subordinado a lo segundo. Ambos son complementarios en una economía terciaria (Frigolé 2011).

La patrimonialización es la base sobre la que descansan diversas formas de mercantilización de lo auténtico, tal como muestra el siguiente ejemplo, con parecido con el anterior.

El lugar calificado como «uno de los más auténticos del mundo» por su propietario, el empresario Ferragamo (industria del lujo), es un burgo del siglo XVII con 1.700 hectáreas de terreno en un valle de la Toscana, que ha sido reconvertido en un complejo vacacional de acceso restringido. Se compone «de 21 villas restauradas a la manera de chalecitos con encanto, una iglesia del siglo XIV con frescos de Pietro Lorenzetti, spa común, piscina, helipuerto, varios restaurantes de comida orgánica, tienda de artesanía y un tapiz de viñedos...» En este marco la firma Ferragamo presentó una línea de productos para el hogar (velas, fragancias para el ambiente, perfumes, etc.) denominada Tuscan Soul. El concepto «espíritu de la Toscana» combina tres factores: «el made in Italy, la fabricación artesanal y los ingredientes naturales» (Martínez-Mora, 2010: 123-124).

La autenticidad del producto reforzada por la vinculación con un territorio considerado auténtico por su paisaje y su historia y la exclusividad del producto realzada por la exclusividad del lugar.

El tercer ejemplo muestra una acumulación de autenticidad como resultado de un doble proceso de patrimonialización.

El protagonista es la firma Zegna, dedicada a la alta costura. La primera patrimonialización tiene como objeto la protección de un animal en vía de extinción, cuya fibra es muy valorada por la firma.

«Zegna busca siempre las mejores materias primas. Su ética, en el extremo opuesto a los ritmos del «fast fashion», ha llevado a la marca a revitalizar la población de vicuñas de Perú y a mejorar la calidad de vida de los campesinos que las crían. (...) Cuando los Zegna llegaron a los Andes, a 5.000 metros de altura, donde vive en estado semisalvaje la vicuna, sólo pastaban 
libremente unos 5.000 ejemplares». «Mataban a los animales y vendían toda la piel de contrabando». (...) La marca italiana presentó entonces una propuesta al Gobierno peruano para relanzar la vicuńa al mercado. (...) El acuerdo incluye la construcción de un sistema de irrigación en plena cordillera de los Andes que garantiza una vida mejor a los criadores y suficiente alimento para las vicuñas. Ahora se cuentan 120.000 ejemplares, que es una cifra que salva a la vicuña del peligro de extinción» (Vázquez, 2009: 92-96).

La protección de la vicuña es la condición sine qua non para un aprovisionamiento sostenido de su lana y un cierto monopolio sobre ella. La protección garantiza el suministro de una fibra autóctona, natural, de gran calidad, etc. La narración de la iniciativa de patrimonialización llevada a cabo por los Zegna forma parte del proceso de mercantilización de lo auténtico.

El segundo proceso de patrimonialización llevado a cabo por Zegna tiene como objeto la protección del entorno de su fábrica, mediante la creación de un parque protegido de cien kilómetros cuadrados abierto al público, llamado el «Oasi Zegna». La compatibilidad entre parque y fábrica se basa en que el aire y el agua salen de la fábrica sin contaminación.

Las diversas actuaciones de la firma para la conservación de la naturaleza proyectan sobre la marca y sus productos un aura de gran autenticidad, necesaria para convertirse en una referencia de exclusividad, condición del lujo. La patrimonialización de la naturaleza proporciona referentes de autenticidad que legitiman la publicidad directa de sus productos. Una de ellas consiste en una foto de gran tamaño de un hombre de perfil vestido con un traje completo que contempla un paisaje difuminado, que se especifica que es del «Oasi Zegna». Al pie de la foto el lema: Pasión por la Naturaleza (Le Monde, 5 de octubre de 2012).

El ejemplo de Zegna contiene aspectos que son también relevantes en el último caso que expongo a continuación. Se trata de una narrativa que tiene como protagonista principal la empresa de cosmética Chanel y como protagonista auxiliar una ONG. El escenario es la isla de Madagascar en cuya selva crece el jengibre azul, cuyo rizoma se ha convertido en un elemento valioso. En 2004, especialistas de Chanel, que recorren la selva en busca de nuevos activos naturales, descubren el jengibre azul, del que se conocían ya sus propiedades cicatrizantes. El examen del rizoma permitió descubrir propiedades anti-inflamatorias y anti-oxidantes que protegen de los radicales libres responsables del envejecimiento de la piel. La narrativa califica el descubrimiento de milagroso. 
Se trata de un tesoro auténtico, al margen todavía de la circulación mercantil, de un factor de producción original, natural, que dará origen a una mercancía auténtica. Pero es un tesoro amenazado por las prácticas agrícolas de la población local, que implican una progresiva deforestación de la selva.

Chanel será el salvador del jengibre azul y lo logra asociándose con la ONG franco-malgache "El hombre y el medio", que desde 2002 trabaja en la protección y recuperación de la selva. La asociación asegura a Chanel el suministro del rizoma del jengibre azul mediante la implicación de la población local en el cultivo y la recolección del jengibre. Chanel invierte además en programas de salud, educación y en la creación de un taller de cestería para mujeres, con el fin de preservar su saber y técnica ancestrales y favorecer el comercio, y financia también programas de replantación de árboles de la ONG.

En la narrativa dos aspectos van juntos: la salvación de un tesoro natural y el desarrollo de la población local. El nuevo producto no sólo es bueno como remedio, sino también socialmente, lo que lo hace doblemente auténtico.

El espíritu de descubrimiento es esencial para el hallazgo de «riquezas» no convencionales que puedan ser comercializadas bajo la etiqueta de lo auténtico y además hay que asegurar un suministro continuado o regular, dado que inicialmente no son mercancías, o si lo son, forman parte de un mercado irregular y lejano.

La autenticidad es un referente fundamental para la creación de valor económico y también político, aspecto este que no abordo en este texto.

\section{Consideraciones finales no concluyentes}

¿Qué tipos de industrias necesitan hacer más referencia a la autenticidad y utilizan más las retóricas de la autenticidad?

En primer lugar la llamada industria del lujo, relacionada con la creación y mantenimiento de la máxima distinción social. Los referentes de autenticidad que usa esta industria son múltiples y diversos: materias primas naturales, trabajo artesano, vinculación a un territorio específico, modalidades diversas de patrimonialización de la naturaleza y la cultura, producción limitada, consumo restringido, etc. 
En segundo lugar, los llamados «sectores ecológicos emergentes», uno de los cuales es el turismo sostenible, ecoturismo o etno-turismo. Un ejemplo: el Banco Interamericano de Desarrollo a través del Programa Andes Tropicales promueve el turismo sostenible de base comunitaria, en el que los propios campesinos gestionan las rutas guiadas y los alojamientos. Para ello reciben capacitación y micro-créditos del Fondo de Crédito Verde. El responsable de turismo sostenible del citado banco explica sobre la creación de la infraestructura y el modelo elegido: «La red se cimenta en alojamientos familiares. A estos alojamientos se les da un «sello» característico. «Mucu», en el idioma indígena original significa «el lugar de», por eso decidimos llamar así a los alojamientos. Nos pareció un nombre auténtico y autóctono. Distingue un tipo de alojamiento que creemos que es único, porque permite al turista disfrutar del paraje de forma más auténtica, convivir realmente con la comunidad local y conocer de cerca sus costumbres. Se trata de un turista que busca conocer el país de la forma más auténtica y original posible, concienciando además con la contribución a la mejora de la calidad de vida de los habitantes locales» (Martín, 2010: 48). El responsable del banco usa dos pares de adjetivos «autóctono y auténtico» y «auténtico y original» para caracterizar a esta modalidad de turismo?

El que se trate de una iniciativa del Banco Iberoamericano de Desarrollo pone de relieve la importancia de la política económica. La reubicación de la economía de la autenticidad en el marco de una economía política de la autenticidad permite dar cuenta del protagonismo del estado y de las instituciones transnacionales en relación al descubrimiento y creación de nuevos tipos de riqueza, así como también de la apropiación de ella por parte de ciertos sectores de una población y la marginación de otros. Una referencia breve a otro ejemplo reafirma la importancia de la economía política de la autenticidad. El desarrollo del etno-turismo «mapuche» en Chile es el resultado de una «co-producción que llevan a cabo el estado chileno y asociaciones de microempresarios mapuches» (Aguilera, 2012: 42), pero fue el estado quien eligió e impulsó el modelo de microempresas mapuches y también el modelo de «desarrollo de los pueblos indígenas basado en la exhibición de la «identidad» (Aguilera, 2012: 40).

9 Me he centrado en la relación entre economía política e ideología de la autenticidad, sin entrar en el debate de los estudios sobre turismo a partir del texto de MacCannell (1973) sobre autenticidad escenificada y cultura auténtica, ni en la discusión sobre categorías de autenticidad objetiva, simbólica, existencial e inautenticidad (postmodernismo) (Rickly-Boyd, 2012: 272-73). 
La gran producción utiliza referentes de autenticidad para la comercialización de productos diferenciados. El marketing verde utiliza imágenes de la naturaleza salvaje e inaccesible como un atractivo de ciertos productos, aunque no siempre resulta efectivo. Un tribunal francés ha ordenado recientemente a Toyota la retirada de la publicidad de sus coches $4 \times 4$, dado que considera que su asociación con diversas imágenes de una naturaleza salvaje incitan a comportamientos contrarios a la protección del medio.

Mary Douglas afirma que «el estilo apropiado a un determinado mensaje coordina todos los canales a través de los cuáles éste se transmite» (1978: 96). En este caso, autenticidad, como ideología, define un estilo y una retórica. El mensaje es el valor que los diversos canales transmiten, coordinados por el estilo, para su consumo como distinción social. Entre los canales están la moda, la agricultura ecológica, el ecoturismo, la industria del lujo, la patrimonialización de edificios, objetos, naturaleza, rutas, etc.

Finalmente, una breve consideración sobre el objeto de estudio de la antropología, que en algunos de los ejemplos expuestos está constituido por una red transnacional de protagonistas e intereses. Retomo el ejemplo referido a Oaxaca: el primer protagonista lo constituyen diez comunidades en la sierra de Oaxaca, que habitan un ecosistema de bosque mesófilo de montańa, vulnerable al cambio climático y la deforestación, y de las que el imaginario de autenticidad destaca su identidad indígena. El segundo protagonista, investigadores ambientales y asociaciones como ProNatura que ofrecen capacitación, instrumentos de medición de captura de dióxido de carbono y carbono, instrumentos legales, etc., a las comunidades indígenas. El tercer protagonista, empresas existentes en otros territorios que compensan sus emisiones con la compra de certificados ambientales a las comunidades indígenas. Esta trama de dependencias, percepciones, intereses, etc., diversos constituye una totalidad, que para ser investigada en toda su extensión y complejidad necesitaría quizás de redes o coaliciones transnacionales de antropólogos. Todo ello constituye un buen reto para la Antropología del siglo XXI.

\section{Bibliografía}

Aguilar, A. (2012). «John Varvatos. Masculino singular» El País Semanal n.o 1881, 14 de octubre, 21-22. 
Aguilera, I. (2012). El ingrediente mapuche. De la cocina al estado-nación. Tesis Doctoral. Universitat de Barcelona.

Aubertin, C., Boisvert, V., Vivien F.-D. (1998). «La construction sociale de la question de la biodiversité» Natures, Sciences, Sociétés 6,1, 7-19.

Bindi, L. (2012). "Cheval-patrimoine. Culture, territoire, économie d'une relation homme-animal» en Beatriz Santamarina (ed.), Geopoliticas patrimoniales. Una mirada etnográfica. Valencia: Germania, pp. 197-213.

Boltanski, L., Chiapello, E. (2002). El nuevo espíritu del capitalismo. Madrid: Akal.

Comaroff, John and Jean. (2011). Etnicidad S. A. Madrid: Katz.

Davallon, J. (2010). "The Game of Heritagization», en X. Roigé y J. Frigolé (eds.), Constructing Cultural and Natural Heritage. Parks, Museums and Rural Heritage. Girona: ICRPC, pp. 27-38.

Douglas, M. (1978). Simbolos naturales. Exploraciones en cosmología. Madrid: Alianza.

Dupré, L. (2005). «Classer et nommer les fruits du châtaignier ou la construction d'un lieu à la nature»Natures Sciences Sociétés 13, 395-402.

Fernández, J. (2012). «El vino está de moda. Once grandes del viñedo español hablan de estilo» El País Semanal n. ${ }^{\circ} 1881,14$ de octubre, 46-53.

Frigolé, J. (2010). «Patrimonialization and the Mercantilization of the Authentic. Two Fundamental Strategies in a Tertiary Economy», en X. Roigé y J. Frigolé (eds.), Contructing Cultural and Natural Heritage. Parks, Museums and Rural Heritage. Girona: ICRPC, pp. 27-38.

- (2012). "Cosmologías, patrimonialización y eco-símbolos en el Pirineo catalán en un contexto global» Revista de Antropología social 21, 173-196.

Harvey, D. (2004). La condición de la postmodernidad. Investigación sobre los orígenes del cambio cultural. Buenos Aires: Amorrortu.

Heinich, N. (2012). La fabrique du patrimoine. Paris: Éditions de la Maison des Sciences de l'Homme.

Herzfeld, M. (1999). Anthropology through the Looking-Glass. Critical Ethnography in the Margins of Europe. Cambridge: Cambridge University Press.

Kirshenblatt-Gimblett, B. (2001) «La cultura de les destinacions: teoritzar el patrimoni» Revista d'Etnologia de Catalunya, 19, 44-61.

Lefeuvre, J.-C. (1990). «De la protection de la nature à la gestion du patrimoine naturel», en Patrimoines en folie. Henry Pierre Jeudy (Sous la direction de), París, Édition de la Maison des Sciences de l'Homme, pp. 29-75.

MacCanell, D. (1973). «Staged Authenticity: Arrangements of Social Space in Tourists Settings» The American Journal of Sociology, 79, 3, 589-603. 
Martín, L. (2010). «Hacia la conservación ambiental y social a través del turismo» Compromiso Empresarial, 31, noviembre-diciembre, 46-48.

Martínez-Mora, I. (2010). «Del campo a casa. Ferragamo apuesta por la diversificación» El País Semanal, n.o 1752, 25 de abril, 123-124.

Marty, P.; Vivien, F.-D.; Lepart, J. et Larrère, R. (Eds.). (2005). Les Biodiversités: objets, theories, pratiques. Paris: CNRS Éditions.

Murdoch, J.; Marsden, T. and Banks, J. (2000). «Quality, Nature, and Embeddedness: Some Theoretical Considerations in the Context of the Food Sector» Economic Geography, 76, 2, 107-125.

Murdoch, J. and Miele, M. (1999). «Back to Nature»: Changing «Worlds of Production» in the Food Sector» Sociologia Ruralis, 39, 4, 465-483.

Pinton, F. (2001). «Conservation of Biodiversity as a European Directive: The Challenge for France» Sociologia Ruralis 41, 3, 229-342.

Rickly-Boy, J. (2012). "Authenticity and Aura. A Benjamín Approach to Tourism» Annals of Tourism Research 39, 1, 269-289.

Rivas, R. (2011). «Amor a los vinos desnudos» El País, 7 de octubre.

Rodríguez, J. (2011). «Redzepi. El señor de los fogones» El País Semanal no 1827, 2 de octubre, 32-43.

SaIle, B. (2010). «Hasta el jabón está hecho a mano» El País, El Viajero 2 de marzo, 14.

VÁsquez, K. (2009). "Guardianes de la lana» El País Semanal, n. ${ }^{o}$ 1694, 15 de marzo, 92-96.

Van Koppen, K. (2000). «Resource, Arcadia, Lifeworld. Nature Concepts in Environmental Sociology» Sociologia Ruralis, 40,3, 300-318.

Wolf, E. (1987). Europa y la gente sin historia. México: FCE.

Woolard, K. (2008). «Les ideologies lingüistiques: una visió general d'un camp des de l'antropologia lingüistica» Revista de Llengua i Dret, 49, 179-199.

Recibido: 4/2/2013

Aceptado: 15/3/2013 